\title{
RACIONALIDAD TECNOLÓGICA, RESPONSABILIDAD ÉTICA Y DERECHO POSTMODERNO*
}

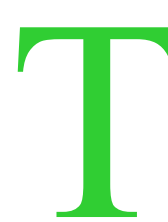

ratar de reflexionar acerca de las posibles interrelaciones entre racionalidad técnico-científica, responsabilidad ético-social y comunicación jurídica es algo que se orienta y tiende desde una perspectiva preferentemente jurídica, más que nada, a la propia utilidad; es decir, como aportación tendente a proporcionar al investigación.

jurista investigador su propia certidumbre en cuanto al objeto de su

Mas, por encima de todo, lo que realmente aquél desea es ser entendido como oferta de diálogo interdisciplinar, como exigencia que ayude a superar al menos de forma lenta y progresiva el confuso babel terminológico resultante, procedente de esa especie de híbrido que es el homo faber.

Por una parte, al parecer, existen buenas expectativas al respecto. La física, que en palabras de Ilya Prigogines ${ }^{2}$ describe un mundo en su concepción moderna clásica «que no sabe qué hacer desde el momento en que empiezan a aparecer estructuras organizadas», descubre hoy en una forma nueva los fenómenos del tiempo, la diversidad y la complejidad. $\mathrm{Y}$ éstas son precisamente las categorías centrales de la problemática con las que se encuentra confrontado el jurista investigador, por cierto bajo una terminología conceptual tan vetusta como la de «libertad», «individuo», «pluralismo»y «previsión».

Por la otra -y esto se asume como una conquista moderna, al par

* Lección magistral sobre Lichtenberg, pronunciada en la Escuela Técnica Superior de Darmstadt el 22-10- 1991.

${ }^{2}$ Ilya Prigogine. Isabelle Stengers, Dialog mit der Natur. 5. a ed., 1986, Prefacio pág. III. 
que como reflexión sobre la maldición babilónica ${ }^{3}$ - se habla «de una forma de expresión últimamente empleada en la Filosofía jurídica con preferencia» ${ }^{4}$, que describe lo jurídico bajo la categoría de «constructivismo social» en función de un sistema social autopoyético que de momento y en su hermetismo operativo no sólo se distancia de toda normatividad moral y política ${ }^{5}$, sino que incluso llega a poner en solfa, desde su propia perspectiva, toda competencia cognitiva vinculante (en cuanto al Derecho se refiere) respecto a la realidad, viva o inerte, incluyendo, por supuesto, a las Ciencias naturales. «Desde el punto de vista constructivista no existe posibilidad alguna de poner en tela de juicio la autoridad científica del Derecho, ni desde las propias realidades sociales, ni desde la experiencia cotidiana y menos aún desde la experimentación científicamente controlada»- estas son palabras de Gunther Teubner ${ }^{6}$. ¿Acaso es ésta la manera ideal de destacar un purismo metodológico intencionadamente circular, por así decir, de una nueva «Teoría pura del Derecho», ahora bien, no como Teoría de las normas sino del conocimiento de lo social; o se trata quizá más bien de la arrogancia del poder disfrazada apenas de jerga lingüística de tipo prescriptivo o, incluso al revés, es la pura expresión de la experiencia de impotencia socrática? En todo caso, se muestra como una ironía del desarrollo científico el hecho de que justo aquella teoría del Derecho de cuño progresista, la teoría de los sistemas autopoyéticos, teoría que por primera vez rompe los lazos que le unen tradicionalmente con las ciencias naturales, reconozca de plano su entronque original con las teorías biológicas respectivas.

Intentemos comprender el sentido de la tan encomiada pretensión epistemológica del «constructivismo social» en base al trasfondo del desarrollo contemporáneo del Derecho y de la conciencia, que se acostumbra a caracterizar como "proyecto de modernidad» ${ }^{7} \mathrm{y}$, en parte también «proyectos de la ilustración»" ${ }^{8}$, y que en opinión de numerosos sociólogos y filósofos americanos y franceses debe haber llegado ya a su fase postrera mediante el tránsito a la posmodemidad'.

${ }^{3}$ Libro de Moisés, 11 .

${ }^{4}$ Immanuel Kant, Werke, edit. por W. Weischedel, tomo III, 1959, pág. 377.

5 Gunther Teurbner, Die Episteme des Rechts, en: D. Grimm (ed.), Wachsende Staatsaufgaben-sinkende Steuerungsfähigkeit des Rechts, 1990, pág. 131; vid. aportaciones en: S.J. Schmidt (ed.), Der Diskurs des Radikalen Konstruktivismus, 3. a ed., 1991.

${ }^{6}$ Teubner, cfr. n. 4, pág. 132.

${ }^{7}$ J. Habermas, Die Moderne -ein unvollendetes Projekt, Philosophisch-politische Aufsätze 1977-1990, 1990.

${ }^{8}$ Heiner Hastedt, Aufklärung und Technik, Grundprobleme einer Ethik der Technik, 1991.

${ }^{9}$ Daniel Bell, Michel Foucault, Jean François Lyotard -por sólo citar tres de los nombres más relevantes. 
$\mathrm{Su}$ integración dentro de la historicidad de su desarrollo permite reconocer con mayor precisión los puntos de engarce de los que se desgajaron las concatenaciones originales con la moral, la política, el Derecho y los conocimientos técnico-científicos; en ellos se apoya la esperanza de entender los requisitos que posibilitan otras nuevas y más duraderas vinculaciones o, cuando menos -para seguir con la imagen marcial de Teubnerla esperanza de poner fin a las «batallas en la guerra epistemológica» ${ }^{10}$.

Con la tesis de que «es una ingenua hipótesis de la realidad el hecho de que actores humanos configuren los elementos básicos de la sociedad», puesto que más bien son los discursos sociales en sí los «nuevos sujetos epistemológicos», con esta tesis -decimos- se despide de forma radical la teoría jurídica de los sistemas autopoyéticos ${ }^{11}$, de aquella teoría mantenida durante siglos sobre el contrato social de la modernidad, basada en una naturaleza racional -teoría que aproximadamente desde Hobbes (De iure, 1642; Leviathan, 1651) hasta Kant y Fichte (Fundamentos de Derecho natural, 1796) ha sido referencia básica indubitable y punto de partida en toda discusión en torno a las funciones del Estado y de las libertades públicas, últimamente reformulada de nuevo a la luz de la teoría de la Justicia de Rawls (1979)-. Una despedida de esta envergadura no resulta fácil en modo alguno, por lo que damos por supuesto que se apoya en «buenas razones», quizá incluso en pretendidas razones de necesidad.

\section{II}

Al concentrar en este lugar como en un foco unas pocas categorías básicas (lo que presupone reducir a la vez el campo visual), permítasenos presentar el núcleo de esta teoría del Estado y de la sociedad de cuño contemporáneo (que aparece en parte como experiencia filosófica y, en parte también, como axioma político-moral), bajo la siguiente tríada ideal: (1) Autonomía del sujeto individual como centro volitivo y de actuación, (2) Universalización de la razón, incluso a nivel práctico, y (3) Equiparación en calidad de «súbditos» (Hobbes y también Kant), o de «ciudadanos» (Rousseau).

Se ha descrito de forma muy precisa el origen común de ellas, a tenor de la cual en la versión hobbesiana el acto que representa el momento de creación del Estado no sólo produciría al soberano como personalidad del Estado y, por ende, como sujeto jurídico, sino que, simultáneamente conduciría a los individuos que sellan el pacto

\footnotetext{
${ }^{10}$ Teubner, cfr. n. 4, pág. 139.
}

${ }^{11}$ Ibíd., págs. 117 y 130. 
social desde el estado de naturaleza al estado civil, es decir, a aquél en el que son sujetos y objetos del Derecho ${ }^{12}$.

El Soberano como «máximo sujeto» o como «divinidad mortal», encarna en su persona a todos los individuos que le constituyen, en todo caso, respecto de materias incluidas en el ámbito de la «paz y de la seguridad general». Esto es -dice Hobbes- «algo más que un mero apoyo general o que un consenso: se trata de unificar de forma real a todos en una y misma persona, que se hace efectiva mediante el pacto de todos y cada uno entre sí...». La sumisión de cada sujeto por separado bajo la voluntad (absoluta) del Soberano y, con ello, la vinculatoriedad de la ley, no se justifican en modo alguno desde el punto de vista de su corrección o de la justicia dimanante de su propio contenido, sino desde la dependencia constitutiva de los sujetos pactantes. La proclamación de la obediencia a la ley destruye simultáneamente, con el acto básico de la representación, la condición de sujeto jurídico de cada individuo. Esta dependencia se evidencia incluso a través de la prueba hipotética de veracidad/certidumbre a la que Kant somete los pactos del legislador, es decir, del monarca. En ella no será el consenso real de súbditos/ciudadanos la condición positiva de la Justicia (hoy diríamos de la constitucionalidad) de una ley, sino el resultado negativo que debe confeccionar para sí mismo todo monarca legislador, según el cual la ley no debe ser formulada «de forma que todo un pueblo se vea imposibilitado a darle su aprobación», «sea cual fuere su grado de repulsa» ${ }^{13}$. Aquí aparece por supuesto el Kant liberal de 1784 (cinco años antes de la Revolución francesa) con todo su empuje, preconizando la autonomía del sujeto individual junto con el programa racional de la «época de la ilustración» que se basaba en el «sapere aude» (atrévete a usar tu propio entendimiento); aquí entraría incluso la crítica racional públicamente manifestada, sobre la legislación. Pero he aquí que entonces aparece el contraargumento federiciano de «razonad todo lo que queráis y sobre cualquier tema, pero obedeced», asumido sin objeciones por los súbditos prusianos en Königsberg en base al «numeroso y bien disciplinado ejército del monarca, garante del orden público» ${ }^{14}$. La idea de que es necesario todo un proceso público, real y permanente, de formación de voluntades

${ }^{12}$ Thomas Hobbes, Leviathan, edit. I. Fetscher, cap. 17, pág. 134, allí las citas siguientes. Cfr. Karl-Heinz-Ladeur, Selbstorganisation sozialer Systeme und Prozedualisierung des Rechts, en: Grimm (ed.), n. 4, págs. 187 ss., 189 con ulterior bibliografia Bernard Willms, Revolution und Protest oder Glanz und Elend des bürgerlichen Subjekts, 1969, espec. págs. 15 ss.

${ }^{13}$ Kant, Über den Gemeinspruch:... en: kleinere Schriften zur Geschichtsphilosophie Ethik und Politik, ed. K. Vorländer, 1959, págs. 95 y 97.

${ }^{14}$ Kant, Beantwortung der Frage: Was ist Aufklärung?, Werke (vid. n. 3), Tomo IV, 1964. págs. 53 ss. y 61 . 
y opiniones, abierto a la crítica en todos sus flancos, apto para producir ante todo el Estado y su legislación, o sea, la idea de un status constituens de corte democrático, no habría sido para Kant, en modo alguno, puro sueño utópico.

Nadie como Hegel, el crítico de la teoría del pacto social ${ }^{15}$, ha visto que el problema básico del Estado moderno -y también, por tanto, del nuestro actualmente- es la infinita tensión entre la pluralidad de intereses particulares y los esfuerzos por alcanzar el poder, por una parte, y por otra, la unidad de un sistema social a cuál más complejo, que puede ser determinado en su «totalidad» para llegar a ser operativo. «El principio de los Estados modernos posee tal extrema potencialidad y profundidad que permite al principio de subjetividad realizar hasta el máximo la particularidad personal autónoma y, al propio tiempo, conducirla a la unidad substancial y mantener así esa unidad en sí mismo». Evidentemente su respuesta no deja el menor resquicio de duda, de cómo el macrosujeto «Estado» debe ser concebido. «La personalidad del Estado es sólo en realidad la de una persona: el monarca» ${ }^{16}$. En la teoría hegeliana del «Estado personal» se encuentran de hecho vinculadas de forma ideal aquellas dimensiones que determinan hoy también el espacio de acción tanto del individuo como de la sociedad en su totalidad. Para salir al paso de posibles malentendidos debo añadir: por desgracia ese Estado personal, tal y como lo exige y concibe Hegel, no existe, ni tampoco ha existido ni existirá. De ahí que la teoría hegeliana sea una utopía que se desnaturaliza -cuando se la confunde con cualquier tipo de realidad históricaen forma necesariamente «ideológica». Las teorías decimonónicas del Estado y de la sociedad también incluso las contemporáneas de los años sesenta, nos ofrecen toda una gama de ejemplos. La teoría del «reino de las reformas sociales» de L. von Stein (1850), a quien E.R. Huber toma como primer gran apologeta del principio del Estado Social ${ }^{17}$, es hoy nuevamente una de las más influyentes. La teoría steiniana, posterior a Hegel, ostenta una doble vertiente ideológica: primero, por partir de la posibilidad de un poderoso actor social unificado, que no debe ser entendido «desde su ser intrínseco como

${ }^{15}$ G.W.F. Hegel, Grundlinien der Philosophie des Rechts, pág. 258.

${ }^{16}$ Ibídem, pág. 260.

${ }^{16}$ Ibídem, pág. 279 (destacado por el propio Hegel).

${ }^{17}$ Ernst RudolfHuber, Lorenz von Stein und die Grundlegung der Idee des Sozialstaats, en: Nationalstaat und Verfassungsstaat, 1965, págs. 127 ss. El texto hace referencia a otro dado a conocer durante el semestre de invierno 1941/42, publicado después en 1958. Vid, además, E.W. Böckenforde, Lorenz von Stein als Theoretiker der Bewegung von Staat und Gesellschaft zum Sozialstaat, en: Recht, Staat, Freiheit, 1991, págs. 170 ss., 1. ${ }^{\text {a edición en } 1963 .}$ 
guiado por ningún tipo de interés social» ${ }^{18}$, y segundo, porque dicho extraño ser debe ser «el rey» propiamente dicho, el monarca, representante de la concepción «autónoma» o de la «idea pura del Estado», hallándose «por encima de las clases sociales y de sus contradicciones $\gg{ }^{19}$-y ello en un momento en el que la sociedad burguesa ya se había constituido desde hace tiempo en Francia como sujeto político con pretensiones de monopolio universal, si bien en Alemania ello no era así en toda su extensión.

Las utopías, y aquí incluimos también la hegeliana, presentan los momentos que en la realidad sólo se dan en forma de situaciones relativas, imperfectas e «impuras»; es decir, vinculadas al paradigma de ubicación espacio-temporal (por así decir, como el mineral dentro de la roca), de forma estática y no susceptible de proceso alguno de perfeccionamiento, como el estado de absoluta pureza. De ahí que las utopías no sólo carezcan de lugar de ubicación sino incluso de tiempo, mostrándose como realidades estáticas, incapaces de procesamiento, siendo, por así decir, U-cronías. En la utopía hegeliana el Estado no es sólo la «realización de la eticidad ideal», el sujeto moral absoluto, sino también la voluntad sustancial real, la «autoconciencia elevada a generalidad»y, con ello, lo razonable «en y para sí». De esta manera se llega a la unidad de la «moralidad absoluta», autoconsciente y refleja, de racionalidad absoluta y, en la medida en que «se produce aquí el mayor grado de libertad jurídica», se produce también simultáneamente una Justicia absoluta -como dice Hegel-, «un absoluto e inmutable fin en sí mismo» ${ }^{20}$. Si esto no fuera sólo pura elucubración intelectual nos hallaríamos realmente ante un momento divino en el que la historia se detiene; o sea, ante el mismísimo retorno a la época dorada.

\section{III}

Como trasfondo de este pensamiento idealista de totalidad, cuyos efectos posteriores pueden hallarse sobre todo en el ámbito de la categorización científico-jurídica hasta bien entrada nuestra época, se hace patente el gran decalage que asumimos objetiva y subjetivamente respecto del modelo de Estado y sociedad de la modernidad (evito el fácil lapsus linguae: ... «que hemos realizado»).

${ }^{18}$ Lorenz von Stein, Geschichte der sozialen Bewegung in Frankreich von 1789 bis auf unsere Tage, Tomo III (1850), edición de 1959, pág. 37.

${ }^{19}$ Lorenz von Stein, n. 18, págs. 37 y 40.

${ }^{20}$ Hegel, op. cit., en n. 14, págs. 257 y 258. 
La hipótesis que orienta nuestro ulterior interés en la cuestión podría formularse eventualmente así: la patente discrepancia entre las exigencias de prestaciones que se esperan del Estado moderno capitalista, tecnológicamente dependiente, políticamente calificado de «pluralista» y cada vez más multicultural; y la capacidad real de prestaciones de sus instituciones y de sus conceptos político-jurídicos básicos (como, por ejemplo, los de representación parlamentaria, división de poderes, Derechos fundamentales, etc.), tal discrepancia no es sólo un resultado histórico casual resultante de un desarrollo político-económico -y también técnico- que pueda caracterizarse mediante conceptos clave tales como soberanía democrática por un lado, y creciente división del trabajo y de la productividad, y «explosión de los intereses de grupo» por otra ${ }^{21}$. Nuestra hipótesis apunta más bien al hecho de que el desarrollo de aquellos «factores reales» (Max Scheler) ${ }^{22}$ se origina mediante profundas transformaciones de la estructura de la conciencia, de la propia comprensión del saber y de la ciencia y -expresémoslo con cautela-, de las direcciones de nuestro sentido moral. Puede ser que se den relaciones causales cambiantes entre los factores individuales; no obstante, ni se dejan aislar, ni tampoco aparecen aquí en un primer plano de interés. Si se resumen dichas transformaciones bajo la fórmula de W. Ch. Zimmerli ${ }^{23}$, de «experimento antiplatónico» de la postmodernidad, entonces hay que constatar igualmente que la rama jurídica preponderante actualmente entre juristas que trabajan dentro y fuera de los Tribunales de Justicia, a saber, la dogmática jurídica (todavía), no forma parte del experimento. Esto aclara también la curiosa ausencia de diálogo, incluso la incapacidad -diría yo- que se da entre los juristas prácticos al aplicar la dogmática jurídica, y los puramente teóricos quienes al igual que los enunciadores de la teoría de los sistemas antipoyéticos han logrado conectar con la filosofía postmoderna. Permítanme ahora presentar algunas muestras de esta «no simultaneidad» fundamental. La literatura sobre «la crisis del Estado de Derecho ${ }^{24}$, «la crisis del

${ }^{21}$ Klaus Eder, Prozedurales Recht und Prozeduralisierung des Rechts, en: Grimm, (ed.) vid n. 4, págs. 155 ss. y 173.

${ }^{22}$ Max Scheler, Wesen und Begriff der Kultursoziologie, en: Wissensformen und die Gesellchaft, obras selectas, vol. 8, 2. ${ }^{\mathrm{a}}$ ed., 1960, págs. 17 ss.

${ }_{23}$ Walther Ch. Zimmerli, Das antiplatonische Experiment. Bemerkungen zur technologischen Postmoderne, en: íd. autor, (ed.), Technologisches Zeitalter oder Postmoderne, 1988, págs. 13 ss.

${ }^{24}$ Cfr. Denninger (ed.), Freiheitliche demokratische Grundordnung, vol. I, cap. IV, Theorien zur Krise des freiheitlich-demokratischen Rechstaates, págs. 367 ss. Además: Ingeborg Maus, Verrechtlichung, Entrechtlichung und der Funktionswandel von Institutionen, en: Íd. autor, Rechstheorie und politische Theorie im Industriekapitalismus, 1986, págs. 277 ss., con la literatura allí reseñada. 
Derecho regulador» ${ }^{25}$, la del «¿Adiós al Derecho?» (así; entre signos de interrogación) o, cuando menos, la de la «menguante capacidad de orientación del Derecho» ${ }^{26}$, cubren ya bibliotecas enteras. La otra mitad de sus respectivos anaqueles la ocupan trabajos sobre crisis del Estado de bienestar ${ }^{27}$ o del Estado Social, si bien el desmedido crecimiento de dicho Estado Social es precisamente una de las causas principales de la crisis del Estado de Derecho. Esto, al menos, es lo que se puede leer especialmente en aquellos autores que prefieren hablar de inmediato de la «crisis del Estado moderno», poniendo en tela de juicio, en principio, su gobernabilidad ${ }^{28}$; o que, como E. Forsthoff se conforman con una advertencia dirigida el Estado como mero recordatorio resignada en parte $\mathrm{y}$, también en parte, intimidatoria, tendente al dominio de la «realización técnica» ${ }^{29}$. Otros observadores menos resignados analizan el «Estado de Seguridad» como compensación de la «sociedad del riesgo» o del «Estado preventivo» o, dicho de otro modo, del «Estado dirigente», como niveles de desarrollo que van más allá del mero intervencionismo del Estado Social ${ }^{30}$. Una opinión al respecto, publicada no hace mucho y sensible a estos extremos, aunque dogmática, sobre el «peligro que corre actualmente el Estado de Derecho» entiende, entre otras cosas, bajo ciertos términos un «profundo desconocimiento de las leyes epistemológicas del Estado de Derecho», bosquejadas grosso modo bajo los términos de «aluvión normativo», «temor a la responsabilidad», "pérdida de distancias», «obligatoriedad material», «exageradas expectativas», o «desobediencia civil» ${ }^{31}$. El exceso de producción normativa y de instancias burocráticas actúa también en el ámbito de los «desarrollos

${ }^{25}$ Rüdiger Voigt, (ed.), Abschied vom Recht?, 1983.

${ }^{26}$ Grimm, vid. n. 25.

${ }^{27}$ Habermas, Die Krise des Wohlfahrtstaates und die Erschöpfung utopischer Energien, en: íd. autor, Die neue Unübersichtlichkeit, 1985, págs. 141 ss.

${ }^{28}$ Sobre la discusión en torno a la gobernabilidad cfr. Wilhelm Hennis/Peter Graf Kielmannsegg/Ulrich Matz (ed.), Regierbarkeit, vol. I, 1977, vol. II, 1979; además: Sobre gobernabilidad de las monarquias parlamentarias, v. Cappenberger Gesprüche der Freiherr-vom-Stein-Gesellaschaft, vol. 15, 1979, con aportaciones de Josef Isensee y Hans Meyer; der Zustand des Rechtstaates, Cappenberger Gespräche, vol. 21, 1986, con aportaciones de Peter Badura y Gerd Roellecke.

${ }^{29}$ Ernst Forsthoff, Der Staat der Industriegesellschaft, 1971, págs. 11 ss.

${ }^{30}$ Ulrich Beck, Risikogesellschaft, 1986; Joachim Hirsch, Der Sicherheitsstaat, 1980; E. Denninger, Der Präventions-Staat, en: íd. autor, Der gebändigte Leviathan, 1990, págs. 33 ss.; cfr. además: Gunnar Folke Schuppert, Diskurse über Staat und Verwaltung, en: Staatswissenschaften und Staatspraxis, 1991, págs. 122 ss.

${ }^{31}$ Eberhard Schmidt-Assman, der Rechtstaat, en: Isensee/Kirchhof (ed.), Handbuch des Staatsrechts, vol. I, 1987, pág. 24, marginal 97. 
patológicos», y de la «falta de orientación y hastío». Esta perspectiva típica -podría uno estar tentado a decir- del pensamiento tradicional sobre el Estado de Derecho, necesita, en cierta medida, ser invertida, si se quiere avanzar desde su epifenómenos, cuya existencia no se cuestiona, hacia sus auténticas causas. De esta forma ya no se hará responsable al aluvión normativo y a su aplicación, ni al exceso de «juridificación», por la desorientación y el hastío existente, sino al revés; se preguntará qué tipo de desorientación ha conducido a tal exceso de «juridificación». Dicho sea entre paréntesis: la queja por el aluvión normativo es

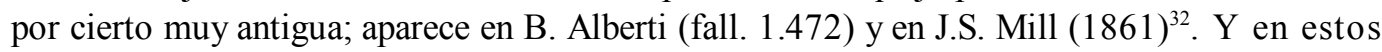
autores no se diagnosticará en absoluto su inclusión dentro de la categorización del Estado de Derecho de cuño constitucional, en base a manifestaciones como las de «desobediencia civil», «exageradas expectativas» o «temor a la responsabilidad», como expresión de un estado social patológico, sino que se investigarán ante todo las causas que figuran en la base de la abierta incongruencia entre las categorías del Estado de Derecho y del propio Derecho, y entre las ideas orientativas de cuño ético-social.

Uno de los fenómenos básicos que aquí se investiga puede ser denominado, de forma breve e imperfecta, «crisis generalizada de la razón». Quizá deberíamos atrevernos a hablar sencillamente del «final de la razón en general». En cualquier caso lo que sí se puede es justificar la diferenciación entre «moderno»y «postmoderno», entre el Derecho de la época de las luces y la Revolución francesa, y el actual Derecho postmoderno -teniendo bien presente que toda división por épocas conlleva en sí el error potencial de ser entendida como expresión de un universalismo histórico-; en ese caso se entenderá como fenómeno del fin de la razón universal, con todas sus concomitancias y secuelas. Ciertamente al hacerlo así no se discute la posibilidad de todo ser humano de comunicarse con otros de forma «razonable»y de decidirse en base a consideraciones y argumentos análogos. Tampoco hay que tocar aquí las categorías kantianas de la razón pura -es decir, teórica- en su función de instrumentos útiles para comprender la realidad, es decir, para su conceptualización. Sin embargo, no existe ya ninguna garantía (¿más?) de que podrán ser usados en todas partes y del mismo modo, al igual que con los mismos resultados prácticos. En el ámbito de las denominadas ciencias exactas o naturales se puede apreciar muy poco este fenómeno; no obstante, en lo tocante a las ciencias sociales, ciencias humanas o culturales (incluyendo aquí a las ciencias jurídicas) esto es ya de por sí

${ }^{32}$ Vid. ulteriores precisiones en Denninger. Staatsrecht 1. 1973, pág. 133, n. 117, y 118 completando. 
evidente. Aquí puede quedar pendiente de decisión si parece oportuno limitar la tesis de la universalidad al ámbito de la razón práctica, toda vez que es éste precisamente el ámbito en el que debe calibrarse necesariamente: a) en primer lugar, la relación de proporcionalidad del Derecho y la moral con la realidad tecno-científica, y b) en el segundo, porque precisamente los progresos epistemológicos obtenidos de esta realidad son los que han colaborado de forma decisiva en la destrucción de la generalización de la razón práctica. Estos asertos requieren una breve fundamentación: comprender los progresos epistemológicos de las ciencias naturales y sociales puede ser entendido como un distintivo de la época moderna de las luces, como condición necesaria del progreso ético-jurídico de la humanidad; mas, en todo caso y hoy por hoy, la conciencia se halla ofuscada respecto del paralelismo que se da en ambos desarrollos ${ }^{33}$.

Tres circunstancias características en el desarrollo del «saber» (de Las Ciencias naturales) han cooperado en la producción de una inseguridad básica en cuanto a la orientación a nivel mundial, y, con ello, en la devaluación de los baremos tradicionales de toda acción -posiblemente también en una sensibilización moral- y, en todo caso, en la conmoción de la razón práctica como patrimonio que posibilita compromisos universales.

1. La primera de tales circunstancias es la constatación de la imposibilidad de dominar con seguridad las consecuencias de la técnica en sus más amplias dimensiones espacio-temporales (y que ya se extienden, en parte, a sucesivas generaciones), Charles Perrow, en su obra de 1984: Accidentes normales. La vida bajo la tecnología de altos riesgos, bosquejó la actual balada en prosa empírico-científica del aprendiz de brujo y, desde la catástrofe de Chernobil sabemos que Goethe y Perrow están totalmente de acuerdo ambos, y con razón, en que el denominado «error humano» es el que trastoca todo sistema, incluidos los sistemas de seguridad.

2. La segunda característica del desarrollo actual del saber y de la Ciencia, cuyos efectos sobre las estructuras del Estado de Derecho y de la función del respectivo «Derecho regulador» debemos elaborar ahora, se deja perfilar grosso modo bajo el rótulo de «explosión de ignorancia». Ciertamente, la ciencia produce saberes en sentido de certeza de algunos o muchos sujetos epistemológicos en cuanto a determinadas materias. En la medida, empero, en que el horizonte de

${ }^{33}$ Sobre la complejidad del concepto «Aufklärung» v. artículo homónimo en: Geschichtliche Grundbegriffe, Historisches Lexikon zur politisch-sozialen Sprache in Deutschland, vol. I, 1972, espec. págs. 265 ss.; Jochen Schmidt (ed.), Aufklärung und Gegenaufklärung in der europäischen Literatur, Philosophie und Politik von der Antike bis zur Gegenwart, 1989. 
tales saberes crece -y en algunos ámbitos lo hace de forma más rápida todavía-, crece también el horizonte de cuestiones sin resolución, el horizonte del desconocimiento, la ignorancia o el no total conocimiento aún $\mathrm{y}$, al par que se incrementa la conciencia de la propia incertidumbre se transforma el punto de vista en cuestión, sumergiendo los aparentemente «resultados seguros» en la penumbra de la eventualidad, de lo ya superado, de un futuro en cierto modo ya acaecido. Jean François Lyotard describe esta (como se ha convenido en llamar desde la perspectiva del desarrollo teórico) «constitución interna de la Ciencia postmoderna», como una paradoja discontinua, catastrófica, no susceptible de rectificación. Es ella pues la que cambia el sentido de la voz «saber» al expresar la forma en que se efectúa dicha transformación. No aporta nada conocido, sino desconocido ${ }^{34}$. Se podría completar esto diciendo que esa ampliación consciente de lo desconocido no sólo tiene lugar en alguna de las zonas marginales y lejanas de la Ciencia, al igual que tampoco se da en cualquier profundo sector de la especulación en torno a la llamada «investigación de partículas», sino en ámbitos de relevancia técnica inmediata, que es tanto como decir de relevancia social e individual. La incertidumbre de si «nosotros» (y se podrá decir, ¿qué sentido tiene esto aquí?) viviremos para ver el colapso de la materia, su implosión en el agujero negro dentro de equis millones o de miles de millones de años (decir «nosotros» es un decir) es algo que muy probablemente trae sin cuidado tanto a los asistentes a esta conferencia como a los demás ciudadanos de fuera. En la jerga de los políticos y demás burócratas legisladores esto significa: «de momento no hay necesidad de ello». La incertidumbre, empero, de si la catástrofe de Chernobil se podría repetir o no próximamente en Polonia, Yugoslavia, Alemania o en cualquier otro rincón del planeta; o cualquier otra incertidumbre similar como la de las posibles consecuencias que acarrearía la pérdida de microorganismos manipulados genéticamente, o de los cambios climáticos del planeta a largo plazo, todo ello permite convertir la capacidad de 'actuación insegura' -como así lo formuló Ulrich Beck-, en una cualificación clave a nivel político y biográfico»» ${ }^{35}$.

El tener que trabajar con inseguridad científicamente formulada y calibrada, sea en forma de porcentajes de riesgo o del factor equis estimado respecto de las consecuencias derivadas de la técnica es algo que acarrea a los juristas bastantes quebraderos de cabeza dejándoles, por así decir, a nivel «personal» (es decir, como seres morales) y a nivel dogmático, a dos velas. Sus consecuencias se describen como «crisis del Estado de Derecho», puesto que el razonamiento

\footnotetext{
${ }^{34}$ Jean-François Lyotard, Das postmoderne Wissen, 1986, pág. 173.

${ }^{35}$ Beck, v. n. 31, págs. 101 ss.
} 
jurídico tradicional en concreto, que se basa en deducciones jerárquicas, en el paso de lo general a lo específico, de la Ley a la casuística, en la subsunción -en una palabra- y en la sentencia reputada justa, e incluso en el acto administrativo formulado a todas luces como imperativo; todo ello ya no parece funcionar en absoluto, ya que, si el causante individual de un daño o de un sólo riesgo no puede ser identificado «con seguridad», si, por tanto, se carece de certidumbre en cuanto al sujeto responsable o, desde una perspectiva policial, en cuanto al «perturbador del orden» responsable, si, por otra parte además el hecho jurídico que conlleva como consecuencia la responsabilidad o el deber de actuar de oficio no puede ser determinado con precisión ya que en lugar de un peligro de perfil bien diferenciado aparece un simple riesgo cuyo grado de probabilidad es tan desconocido como el alcance de los posibles daños; entonces es cuando justamente se vienen abajo las columnas que sujetan ese artístico edificio que es el «derecho regulador»; entonces es cuando empiezan a desdibujarse los límites aparentemente tan claros entre lo prohibido y lo permitido, entre la libertad del ciudadano y el control del Estado, límites de los que el Estado Social debería sentirse tan orgulloso.

Veamos un ejemplo de todo lo dicho, en una sentencia del Tribunal de lo contencioso-administrativo de $\mathrm{Kassel}^{36}$. El Tribunal en cuestión debería decidir sobre la necesidad y la capacidad de obtención de licencia de ciertas instalaciones experimentales de manipulación genética en una época en la que todavía no existía la «Ley sobre técnicas de manipulación genética» del 20 de junio de 1990, que es la base jurídica específica para tales experimentos y que sirve también para elaborar productos farmacéuticos ${ }^{37}$. La solución del caso propuesto, a la luz de los principios tradicionales del Estado de Derecho es bien clara, constatada igualmente por la gran mayoría de los que sometieron a crítica la decisión en cuestión: que una acción «en sí» permitida no necesita ni licencia ni capacidad jurídica, ya que lo que no está prohibido por el legislador por razones obvias de bienestar común está permitido, tanto más cuanto que, como aquí es el caso, se basa en la aplicación de ciertas libertades constitucionales (libertad de ejercer oficio, profesión y actividad económica). Sin embargo, el citado Tribunal decidió algo distinto: en primer término constató de forma precisa que el progreso tecno-científico siempre conlleva «indefectiblemente» cierta carencia de conocimientos, ciertas lagunas del saber humano y cierta eventualidad, es decir, conlleva una falta de

${ }^{36}$ VGH Kassel, Beschluss vom 6.11.1989, JZ 1990, 88, con comentario de H.H. Rupp; NVwZ 1990, págs. 276 ss., con ulteriores reenvíos.

${ }^{37}$ Aquí se soslaya conscientemente la aplicabilidad de principios transitorios hasta la plena vigencia de la Ley de manipulación genética alemana. 
seguridad en los resultados. El trato con este fenómeno del desconocimiento (es decir, del «todavía no saber») no es nada nuevo para el ordenamiento jurídico; sin embargo, la sentencia continúa: «No obstante, en la investigación de materias innovadoras básicas, como la energía nuclear, tecnología espacial, tecnología de información y de comunicación, biología y -en especial- tecnología genética, nos movemos en otras dimensiones y en otros niveles cualitativos distintos ${ }^{38}$.

Dada la peligrosidad especial de dicha tecnología genética -comparada en este contexto con la derivada de la energía nuclear de uso pacífico-, se reputa correcto que sea el propio legislador quien decida en principio sobre la permisividad de dicha tecnología. Si se tuviera que esperar a los resultados experimentales sobre nocividad o utilidad de esta tecnología sería tanto como arrojar a un niño a un pozo y esperar a ver qué pasa antes de actuar. Dicho con pocas palabras: la sentencia invirtió la relación prohibido-permitido, típica en Derecho, de la siguiente forma: «Puesto que la puesta en práctica de este tipo de actividades no está expresamente permitida, sino condicionada a severos controles, debe estar en principio prohibida en función de sus imprevisibles riesgos.»

Aquí aparece un nivel jurídico especial, al trastocarse en «programa de seguridad preventivo». El juez que exige la actividad exclusiva del legislador actúa, sin embargo, como si fuera él mismo el legislador, cuando lo prohíbe por primera vez. Si se quisiera generalizar este principio -y hasta ahora la capacidad de generalización ha sido característica y condición cualitativa de la normatividad jurídico-reguladora del Estado de Derecho-, el ciudadano se vería de inmediato confrontado con el «temor de todo juez al evaluar la técnica» (G. Winter), y muy pronto desconocería dónde se hallan los límites de lo permitido $^{39}$. Al desaparecer el límite clásico de seguridad y previsibilidad del Derecho, que simultáneamente significaría despedirse de la libertad y responsabilidad individual del ciudadano, cambiaría igualmente la seguridad precaria, preventiva, manipulable y contextual, en relación a determinados bienes jurídicos ${ }^{40}$.

La relación entre la generalidad de la Ley, entre el sujeto responsable de sus actos -como así es lo usual en el ordenamiento jurídico de Kant- y la superación técnico-racional del mundo, dicha relación todavía brillaría un último segundo con todo su esplendor, justo en el momento de su destrucción.

${ }^{38}$ Cfr. n. 37, JZ 1990, 90.

${ }^{39}$ Cfr. Gerd Winter, Die Angst des Richters bei der Technikbewertung, ZRP 1987, págs. 425

SS.

${ }^{40} \mathrm{Vid}$. al respecto Denninger, n. 31, págs. 33 ss. 
3. Una tercera característica del desarrollo científico, al tiempo que la última que aquí se va a mencionar, es tan compleja y está tan poco estudiada en todas sus últimas consecuencias que sólo la puedo esbozar aquí con suma cautela y sin ánimo de exhaustividad. Por otro lado, es ésta justamente la que fascina a los juristas, puesto que se trata, dicho grosso modo, de cambiar la proporción «saber-poder». Con todo no intento señalar los siguientes fenómenos extremos observados con frecuencia: a) Que por primera vez en la historia de la humanidad, el desarrollo tecnológico ha alcanzado tal estado que hace posible la autodestrucción de la especie homo sapiens (junto con gran parte de su entomo), y b) que los esfuerzos en hombres y tiempo que conlleva la eliminación de cierto número de seres humanos se ha reducido siempre de forma progresiva ${ }^{41}$. No conviene pasar por alto aquí que ambos hechos han logrado efectos profundos en cuanto a la distribución global del poder y en el ordenamiento jurídico internacional y sus instituciones, y que seguirán lográndolo. Nuestro interés se centra ahora en el fenómeno cotidiano, mucho menos espectacular pero por ello tanto más efectivo, de la creciente implicación de la praxis (o sea, de las estructuras de poder) y del desarrollo científico.

En íntima unión con el final de la generalización de contenidos de la razón práctica y sobre el telón de fondo de modelos tradicionales en fase de desintegración, si no ya fuertemente descoloridos, relativos a la formación de identidades colectivas, como el Estado nacional, la clase social, la creencia religiosa o el partido político ${ }^{42}$, este fenómeno significa un reto apenas reconocido como tal, dirigido a la fantasía del jurista. Categorías básicas como «representación», «bien común», «Soberanía», y también elementos constitutivos del Estado de Derecho como «división de poderes», «Ley» y «Derechos fundamentales», han de ser repensados de nuevo.

Walther Ch. Zimmerli, al opinar que «la época tecnológica determina la otra cara de la medalla de la postmodernidad $\gg^{43}$ ha destacado uno de los aspectos esenciales del fenómeno aquí reseñado: habla de una hibridación entre ciencia y tecnología en donde ya no existirá división entre ciencia como pura producción de conocimientos y técnica, como aplicación de éstos. La línea divisoria entre la «investigación de líneas básicas» y la «ciencia aplicada» se vuelve cada vez más difuminada incluso a nivel teórico. J.E Lyotard ha constatado de forma brutal y sin tapujos que ya no sirve de línea protectora, ni a

${ }^{41}$ Heinrich Popitz, Phänomene der Macht, 1986, págs. 33 ss.

${ }^{42}$ Vid. al respecto Habermas, Können komplexe Gesellschaften eine vernünftige Identität ausbilden?, en: Habermas/Heinrich, Zwei Reden, Aus Anlass des Hegelpresises, 1974, págs. 57 ss.; Íd. en Lyotard, op. cit., n. 35, pág. 53.

${ }^{43}$ Zimmerli, cit. n. 23, pág. 22 y más adelante pág. 24. 
nivel teórico ni en la práctica, de la torre de marfil: «El Estado y/o la empresa han cedido el cómputo de legitimación idealista o humanista (completemos: de las ciencias) para justificar el nuevo punto de partida; en el discurso de los actuales accionistas de hoy, la única apuesta digna de crédito es el poder (la puissance).

Ya no se compran científicos, técnicos ni aparatos para buscar la verdad, sino para ampliar el poder ${ }^{44}$.

De toda esta situación resultan para todo ordenamiento jurídico que, como el constitucional alemán, se base en el «valor y dignidad de la persona», «al actuar como miembro de una sociedad libre, en libre autodeterminación ${ }^{45}$, tareas específicas de protección, que aquí sólo pueden ser reseñadas brevemente en cuanto a sus tendencias:

a) Todo científico que trabaje en régimen de dependencia material -lo que hoy por hoy viene a ser la regla general- debe ser protegido, en cuanto a las convicciones constitutivas de su personalidad, contra toda presión del sistema político-económico. Ello exige el reconocimiento de la capacidad de objetar en conciencia de todo científico en régimen de dependencia laboral, con vigor suficiente como para modificar tal status en ciertas condiciones; a saber, en base a la denominada «subjetividad» (o, mejor dicho) autonomía de la propia conciencia.

El Tribunal Supremo federal alemán ha aplicado ejemplarmente, en mayo de 1989, lo aquí dicho, en un caso en el que se trataba de la negativa de un director de un grupo de investigadores, empleado por una multinacional, a seguir desarrollando un antiemético que no sólo se aplicaría en el tratamiento quimioterapéutico del cáncer sino evidentemente y en mayor medida como tratamiento de primeros auxilios en todo soldado herido de muerte por radiaciones procedentes de explosiones nucleares en una guerra atómica ${ }^{46}$.

b) El ordenamiento jurídico no debe proteger sólo el foro interno del individuo por su identidad personal sino en interés de un abierto y público debate entre riesgos y utilidades, especialmente sobre disponibilidad y capacidad de los científicos (individualmente) en cuanto a comunicación allende los límites del sistema. La sociedad tecnológica depende, por su propia estructura capitalista, en gran medida, de la implicación entre las estructuras de poder y los procesos de adquisición

\footnotetext{
${ }^{44}$ Lyotard, op. cit., n. 35, pág. 135 -paréntesis añadido por mí, E. Denninger.

${ }^{45}$ BVerfGE 65, 1, 41 (Ley alemana del Censo de Población), en vez de citar diversas fórmulas similares.

${ }^{46}$ BAG Sentencia del 24-5-1989, JZ, 1990, págs. 139 ss., con comentarios de Mayer-Maly. Cfr. completando: E. Derminger/Karl Heinz Hohm, Arbeitsverweigerung aus Gewissensgründen, en: Die Aktiengesellschaft, 1989. págs. 145 ss.
} 
de conocimientos. Negarlo o denunciarlo como patologías sería ponerse en peligro de muerte, además de ser un pésimo romanticismo ecológico. Por otra parte no es menos peligroso ocultar informaciones sobre peligros técnicos potencialmente mortales o amenazadores, o sobre riesgos similares dentro de un subsistema, mientras que los productos que los encierran se extienden por todo el mundo. La historia tecnológica -incluso la de Occidente- de lo nuclear y biogenético ofrece múltiples e instructivos ejemplos, desde el escándalo de Pinto, de los años setenta (casi 9.000 muertos en cuatro años), pasando por la inseguridad de la puerta de bodegas de carga del avión DC-10 (346 muertos tras estrellarse), hasta el llamado caso Bart, relativo a un sistema automático, peligroso por defectos de construcción, encargado de regular el tráfico de ferrocarriles de cercanías en la bahía de $\mathrm{S}$. Francisco ${ }^{47}$. Pero miremos ahora lo que sucedió en la reciente historia de la tecnología alemana y nos dará qué pensar. Se trata de la tragedia de la química Clara Immerwahr, primera esposa del premio nobel Fritz Haber, al manifestarse sin éxito durante la Primera Guerra Mundial contra la fabricación de gas venenoso, fabricación en la que trabajaba su esposo $^{48}$. Otro triste ejemplo del pasado reciente nos lo ofrece la «política informativa» (o, mejor dicho, la política de «desinformación») de la empresa Boehringer de Ingelheim/Hamburgo, sobre la peligrosidad del producto conocido como dioxina (TCDD). La historia es siempre la misma: un especialista que trabaja en ello intenta o bien advertir de los potenciales peligros a los demás miembros de la empresa o a la opinión pública. Por ello se ve sometido a presión por parte de la propia empresa, hasta la eventual pérdida de su puesto de trabajo. No pocas veces se llega hasta el suicidio ${ }^{49}$. Hay que comprender que todo ello no puede calificarse tan sólo de simple «tragedia personal» o algo parecido, ni tampoco que se trata de un mero tema de «jornadas sobre técnica y ética», o para la redacción de códigos deontológicos de asociaciones de ingeniería -por muy honorables e importantes que sean todos estos esfuerzos-, sino que aquí es donde debe intervenir el legislador, al producirse un problema estructural de compatibilidades entre subsistemas en colisión o -dicho en términos comprensibles en la vieja Europa: «Se trata de ocuparse de libertades fundamentales en colisión». En este lugar recordaremos que el legislador de Hesse obliga, desde hace ya más de veinte años, a un grupo de científicos especialistas (todos los que participan en

${ }^{47}$ Bart = Bay Area Rapid Transit -nombre de la empresa-. Sobre los ejemplos vid. Hans Lenk, Ethikkodizes für Ingenieure, en: H. Lenk/G. Ropohl (ed.), Technik und Ethik, 1987, págs. 194 ss.

${ }^{48}$ IPPNW, Clara-Immerwahr-Auszeichnung der IPPNW, págs. 8 ss.

${ }^{49}$ Cfr. diario «Der Spiegel», n. 31 y 32, 1991, págs. 102 ss., y 106 ss. 
cátedras e investigaciones universitarias) a calcular las consecuencias más graves del conocimiento científico a nivel del máximo rango -como la vida, salud, coexistencia pacífica-, al par que se exige que todo científico informe a nivel interno (cuando menos) en la Universidad, de todo peligro potencial que pueda serle conocido (Art. $6 \mathrm{Hug})^{50}$.

Esta disposición fue atacada con virulencia en su momento por políticos y científicos de primera fila, llegándose a hablar de la obligatoriedad de convertirse en denunciante, de la restauración de la Inquisición en la enseñanza superior, y de la supresión de la libertad de investigación científica, e incluso de la destrucción de la ciencia como tal ${ }^{51}$. Colegas de Marburgo acudieron al Tribunal Constitucional impugnando dicha norma, norma que había sido concebida expresamente como protección de todo informador científíco. Los magistrados de Karlsruhe reflejaron su postura en conciencia, sensibilizados ante el problema, en una sentencia de veinte folios ${ }^{52}$, cuyo resultado fue la desestimación de plano del recurso interpuesto.

\section{IV}

Aquí concluyo esta exposición. La lista de cuestiones sin resolver es demasiado prolija y crece constantemente por un motivo: la explosión de desconocimiento. De la situación aquí esbozada entre «reconocimiento y Ciencia» se pueden extraer numerosas consecuencias bastante «concretas» de índole organizatoria y procedimental, sobre todo allí donde se requiere coordinación a nivel práctico entre conocimientos empírico-científicos y los dimanantes de las ciencias sociales, tanto si se trata de procedimientos de producción normativa a nivel parlamentario en los que desde hace ya bastante tiempo se viene discutiendo sin resultado satisfactorio. Aquí entraría desde la institucionalización de asesorías tecnológicas (TFA), hasta la fijación de valores límite respecto al reglamento sobre instalaciones de altos hornos y similares, pasando por las disposiciones administrativas de aguas residuales ${ }^{53}$, hasta llegar al nivel de aplicación normativa -por ejemplo, referente a consultas de expertos en materia de inspección de instalaciones nucleares según la Ley de energías nucleares-, siempre

${ }^{50}$ En la forma constitucional ofrecida y de acuerdo con una interpretación restrictiva, dicha norma es perfectamente compatible con la Ley fundamental de Bonn. Vid. BVerfGE 47, 327, 380.

${ }^{51}$ Ibídem, pág. 371.

${ }^{52}$ Ibídem, págs. 366-386.

${ }^{53} \mathrm{Vid}$. al respecto: Denninger, Verfassungsrechtliche Anforderungen an die Normsetzung im Umwelt - und Technikrecht, 1990. 
teniendo a la vista que -como acabamos de ver en Alemania- el titular de licencia administrativa es justamente el que se suele oponerse al acceso de expertos designados por la Administración para la inspección de dichas instalaciones en cuestión ${ }^{54}$.

Así pues, sería por ejemplo un buen incentivo pergeñar las condiciones de composición y funcionamiento de las comisiones de expertos sobre el telón de fondo de la inevitable imbricación entre los conocimientos en las respectivas materias y los intereses económicos y demás circunstancias, puesto que ello sería ideal para cumplir la legislación del Estado de Derecho, aparte que suficiente para una protección eficaz de las libertades fundamentales. La recientemente regulada «Comisión Central de Seguridad Biológica», en base a la ley sobre manipulación genética, de 20 de junio de 1990, supone una oportunidad antes desconocida ${ }^{55}$.

La creciente juridificación actual, la diferenciación procedimental en cuanto a modos de producción normativa propios, la pluralidad de instancias decisoras a veces consideradas meros mandatarios -lo que necesariamente conlleva en parte cierta autonomía del «discurso jurídico»; todas estas manifestaciones no son más que una descripción inmediata del fenómeno. Para justificar esta forma de producción jurídica apenas sí se ha dado un primer paso. Otra cosa sería si se pudiera partir de la base de que el discurso entablado de manera «racional», es decir, basado en argumentos razonables, incluso en buenos motivos racionales, y el consenso conseguido de esta forma en un proceso «limpio», nos pudieran acercar a la «verdad»-léase- a la «Justicia» un paso más en cada caso. Esta hipótesis nuestra tan optimista se basa en el lema kantiano antes citado «sapere aude» y encierra hoy la idea habermasiana de un «poder comunicativo afectivo» que actúa -como dice su autor«sitiando» al sistema político-administrativo, ya que se nutre de una creencia residual en el poder efectivo de una razón general que llega a darse en la práctica ${ }^{56}$. Sin entrar en agudas críticas como, por ejemplo, las de Albrecht Wellmer ${ }^{57}$ sobre la universalidad de la teoría consensual, tenemos que constatar que posturas filosóficas tan distintas como las de Lyotard y Rorty renuncian unánimemente a todas esas premisas. Para Rorty no se trata de llegar a «la verdad»o al «bien común» en abierta y libre

${ }^{54}$ V. al respecto: Decisión del VGH de Kassel del 10-9-1991, 14 R 2081/91, Siemens AG contra el Ökoinstitut de Darmstadt, FAZ del 11-9-1991.

${ }^{55} \mathrm{Vid}$. un buen principio de cambio de criterios jurisprudenciales en la dirección correcta, aparece en la decisión del BVerfG del 27-11-1990 -1 BvR 402/87- (Josefine Mutzenbacher) EuGRZ 1991, págs. 33 ss., y 39.

${ }^{56}$ Habermas, Volkssouveranität als Verfahren. Ein normativer Begriff der Öffentlichkeit, en: íd. autor, op. cit., n. 6, pág. 208.

${ }^{57}$ Albrecht Wellmer, Ethik und Dialog, 1986, págs. 200 ss., y 211 ss. 
polémica intelectual, sino que para él «una sociedad sólo será liberal si se considera satisfecha con el mero hecho de llamar verdadero al resultado de tales polémicas ${ }^{58}$. Lyotard, en cambio, llama al consenso «valor obsoleto y sospechoso» contrario a la Justicia. Por tanto, «debemos necesariamente ponemos de acuerdo a nivel teórico-práctico sobre la Justicia, desvinculándola de todo consenso (sic) » ${ }^{59}$.

No se deberá lógicamente, por tanto, abusar de los aforismos, sino degustarlos como producto del refinamiento espiritual de Pascal. En este sentido me parece que Lichtenberg, protector de esta lección magistral, yendo más allá que Kant y su llamada a la razón, fue capaz de formular el problema (cuya tarea resolutoria hemos planteado aquí) «con una visión postmoderna más clara», si se me permite decirlo así, cuando escribía: «En todo estamento, el conocimiento racional consiste propiamente en la comprensión correcta de todas nuestras necesidades esenciales ${ }^{60}$. cursiva.

${ }^{58}$ Richard Rorty, Kontingenz, Ironie und Solidarität, 1989, pág. 96, ibíd. resaltado en

${ }^{59}$ Lyotard, op. cit., n. 35, pág. 190.

${ }^{60}$ Georg Christoph Lichtenberg, Sudelbücher, edit. por Franz H. Mautner. 1984, pág. 370, J 231, el segundo destacado en el original. 
